
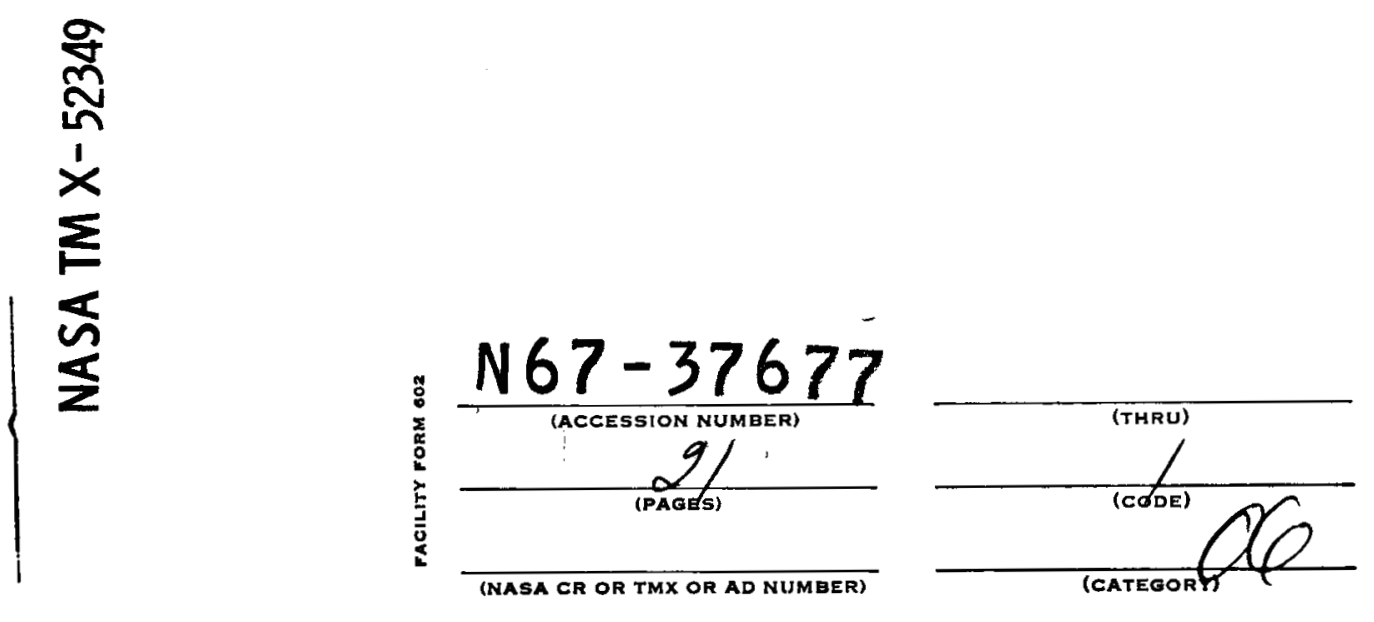

SYNTHESIS OF ULTRAHIGH MOLECULAR

WEIGHT POLY(ETHYLENE TEREPHTHALATE)

by $\mathrm{Li}-\mathrm{Chen} \mathrm{Hsu}$

Lewis Research Center

Cleveland, Ohio

TECHNICAL PAPER presented at Cryogenic

Polymers Conference sponsored by NASA

and Case Institute of Technology

Cleveland, Ohio, April 25-27, 1967 
SYNTHESIS OF ULTRAHIGH MOLECULAR WEIGHT

\author{
POLY(ETHYLENE TEREPHTHALATE) \\ by $\mathrm{Li}$-Chen $\mathrm{Hsu}$ \\ Lewis Research Center \\ Cleveland, Ohio
}

\begin{abstract}
TECHNICAL PAPER presented at
Cryogenic Polymers Conference

sponsored by NASA and Case Institute of Technology

Cleveland, Ohio, April 25-27, 1967
\end{abstract}


Synthesis of Ultrahigh Molecular Weight

Poly(Ethylene Terephthalate)

by Li-Chen Hsu

Lewis Research Center

National Aeronautics and Space Administration

Cleveland, Ohio

Abstract

Poly(ethylene terephthalate) of number average molecular weight of the order of 120000 was prepared from commercial grade material in the solid state with a gas chromatograph apparatus. Parameters studied were the catalyst, particle size, the molecular weight of the starting material, the reaction temperature and time, and the nature and flow rate of the carrier gas.

INTRODUCTION

Poly(ethylene terephthalate), hereafter called PET, possesses physical and mechanical properties that are of considerable interest for special aerospace applications at cryogenic temperatures (refs. 1, 2 , and 3 ). The relation between these properties and molecular weight has not been studied. Mark (ref. 4) has stated that for all polymers certain mechanical properties depend on the average degree of polymerization (DP) or average molecular weight and approach a limiting value of strength at DP's above 600. To study the effect of molecular weight on the cryogenic properties of PET, it was necessary to synthesize PET having a number-average molecular weight of the order of $120000(D P \simeq 600)$. This report covers the research on the method of synthesizing ultrahigh molecular weight material. 
PET is ordinarily prepared by reacting dimethyl terephthalate and ethylene glycol in the melt state and distilling off methanol and the excess of ethylene glycol in two stages (refs. 5, 6, and 7). However, the number-average molecular weight of PET obtained by this method does not normally exceed 30000 (ref. 8), primarily because of some side ester interchange reactions involved (refs. 9 and 10). The method of solid state polymerization was therefore examined as a means of increasing the molecular weight of the material produced by the melt method. In the solid state method, the removal of ethylene glycol can be effected by either employing a high vacuum technique or by flushing with an inert or carrier gas. It was noted that gas chromatograph apparatus is unusually well suited for performing the desorption of the ethylene glycol from the PET molecules. Thus, the gas chromatograph apparatus was investigated as a tool for performing the solid state polymerization. The column of the chromatograph was packed with PET particles instead of the normal absorbent materials.

This report contains a description of the use of a gas chromatograph to perform the solid state polymerization process and presents the results of attempts to produce ultrahigh molecular weight PET. Parameters studied were the catalyst, particle size, the molecular weight of the starting material, the reaction temperature and time, and the nature and flow rate of the carrier gas.

REACTION MECHANISMS INVOLVED IN POLYMERIZING PET

In the melt state, PET molecules bearing terminal hydroxyl groups are capable of carrying out interchange reactions between the hydroxyl 
groups and ester linkages (ref. 9). Another type of interchange between two ester linkages, namely esterolysis, is also possible (ref. 10). These two types of interchange reactions, hydroxyl-ester and ester-ester, may take place either intramolecularly (refs. 10 and 1l) or intermolcularly. In addition, the interchange products in most cases depend upon the position of the reacting ester linkages along the polymer chain. Free ethylene glycol cannot be formed if the reacting ester linkage is in an in-chain position. It can be split off from PET molecules only if a terminal ester linkage is involved. Here terminal ester linkages refer to those nearest the ends of the polymer chains. In certain cases of intramolecular reactions, the products formed from the inchain ester linkages on the same side of the repeating phenylene units as the attacking hydroxyl groups may be different from those on the opposite side. The same is true if the attacking group is another ester linkage.

In table $I$, the possible interchange reactions and their respective products have been listed. No. I is the only reaction which gives the product an increase of number-average molecular weight. All other reactions result either in no change or in a decrease of the numberaverage molecular weight. The decrease in number-average molecular weight is due to the formation of cyclic compounds which are in turn the consequence of certain intramolecular ester interchange reactions. In the melt polymerization of PET, intramolecular reaction has much less chance to take place than intermolecular reactions (ref. 8). 
As the polymer chain grows longer, the number of terminal ester linkages becomes less. In other words, at the final stage of melt polymerization, reactions No. II and VI become predominant. In either of these two ester interchange reactions, there is no net change in the number of interunit linkages before and after the reaction, and therefore no increase in the number-average molecular weight of the product. This explains why the number-average molecular weight of PET prepared by the melt method normally does not exceed 30000 . If a polymerization condition could be found such that only the terminal ester linkages, but not the in-chain ones, are activated, intermolecular reactions No. II and VI would be nearly eliminated. Thus, reaction No. I, as previously stated, remains as the only interchange reaction capable of increasing the molecular weight. This condition can be fulfilled if further polymerization of PET is carried out in the solid state. In the solid state polymerization, the reaction temperature is kept below the melt temperature of PET, but still high enough to activate the terminal ester linkages, so that interchange reactions between the hydroxyl groups of one PET molecule and the terminal ester linkages of another molecule can still take place. In this type of ester interchange reaction, ethylene glycol is split off and the number-average molecular weight is increased.

\section{EXPERTMENTAL PROCEDURES}

\section{Materials}

Reagent grade ethylene glycol was purified by passing through a column of 60 mesh refrigeration grade silica gel at room temperature 
or by distilling under reduced pressure below $100^{\circ} \mathrm{C}\left(373^{\circ} \mathrm{K}\right)$ with a spinning band column. Dimethyl terephthalate was purified by crystallization from ethyl alcohol and sublimed at $0.1 \mathrm{~mm}, \mathrm{mp} 141-142^{\circ} \mathrm{C}$ $\left(414-415^{\circ} \mathrm{K}\right)$. Practical grade tetraisopropyl orthotitanate; reagent grade, zinc acetate dihydrate, antimony trioxide, cobaltous acetate tetrahydrate, methylene chloride, and trifluoroacetic acid were used as received. Pet samples and carrier gases used are listed in tables II and III. Melt Polymerization of PET

Purified dimethyl terephthalate ( 4 moles) and ethylene glycol ( 5 to 10 moles) were charged with catalyst ( 0.01 to 0.05 percent based on dimethyl terephthalate) into a 2-liter 3-neck flask. The melt polymerization procedure is similar to that described in references 5,6 , and 7 and will not be discussed further in this report.

\section{Solid-State Polymerization of PET}

The PET samples were ground with a Wiley mill and separated by conventional sieves into ranges of 4 to 6,18 to 20,60 to 80 , and 80 to 200 mesh (NBS series). The ground particles were packed into the gas chromatograph column with gentle tapping. The column was 16 feet long $(4.9 \mathrm{~m})$ and $3 / 4$-inch $0 . \mathrm{D} .(1.9 \mathrm{~cm})$ and held approximately 300 grams of sample. The melt temperature of each sample was checked with a hot-stage polarized light microscope before starting polymerization.

The general procedure of solid state polymerization with a preparative gas chromatograph (ref. 12) is relatively simple. The 
column packed with PET sample was installed in the chromatograph oven. After the flow of carrier gas was adjusted to the desired rate, the oven was heated and maintained at the reaction temperature for a specified time. Detector and collection trap may be used but are not necessary. The product was allowed to cool with a minimal flow of the carrier gas. It was then stored in a gas-tight container to avoid moisture absorption.

Number-Average Molecular Weight Determination

The intrinsic viscosity $[\eta]$ measurements of PET were carried out in a solvent mixture of trifluoroacetic acid and methylene chloride ( $1: 1$ by volume) with a Ubbelohde viscometer at $25^{\circ} \mathrm{C}\left(298^{\circ} \mathrm{K}\right) . \mathrm{Dr}$. C. J. Heffelfinger of DuPont Company recommended the solvent mixture. Number-average molecular weights $\left(\bar{M}_{n}\right)$ were calculated from MarkHouwink equation: $[\eta]=\mathrm{KM}_{\mathrm{n}}^{\mathrm{a}}$. $\mathrm{K}$ and a were determined by employing a set of PET samples of known number-average molecular weights from 14000 up to 28000 . Their values were found to be $9.2 \times 10^{-4}$ and 0.70 , respectively.

\section{RESUITS AND DISCUSSION \\ Effect of Catalyst}

Coover, Joyner, and Shearer (ref. 13) indicate that an organotitanium compound has to be used as the catalyst in a solid phase polymerization process for preparing linear superpolyesters. The results summarized in table IV, however, show that other commonly used ester interchange catalysts such as zinc acetate-antimony trioxide, and cobaltous acetate are capable of increasing the molecular weights of PET 
as well. This suggests that polymerization of PET in the solid state is essentially the elimination or minimization of undesired interchange reactions involving the in-chain ester linkages. Any type of catalyst which affects the polymerization of $\mathrm{PET}$ in the melt state should be also effective in the solid state as long as the reaction temperature is high enough to activate the terminal hydroxyl groups and those ester linkages nearest the ends of the chains. It is well known that the nature and amount of catalyst used in polyesterification can affect the molecular weight of the product. However, as a great deal of research has been done on catalysts (refs. 14 and 15) for melt polymerization of PET, the knowledge may be applied to the solid-state polymerization as well.

\section{Effect of Initial Molecular Weight}

The results summarized in table IV show that the final molecular weight of the product is very much dependent upon the molecular weight of the starting material. Apparently, in solid-state polymerization the chances for the reacting groups to come together are very much limited and the removal of ethylene glycol is also restrained because of solid phase diffusion problems. Within the same interval of reaction time, the higher the molecular weights of the starting materials, the higher the molecular weights of the products that should be expected.

\section{Effect of Reaction Temperature}

Figure 1 shows the relation between the reaction temperature and the molecular weight of the final product. The starting material had a number-average molecular weight of 16500 . There is no appreciable 
degree of further polymerization below $150^{\circ} \mathrm{C}\left(423^{\circ} \mathrm{K}\right)$ for the period of time studied. The reaction starts around $175^{\circ} \mathrm{C}\left(448^{\circ} \mathrm{K}\right)$ and the molecular weight of the product increases with temperature up to $250^{\circ}$ C $\left(523^{\circ} \mathrm{K}\right)$ which is close to the melt temperature of the PET sample $\left(254\right.$ to $\left.256^{\circ} \mathrm{C}\right)\left(527\right.$ to $\left.529^{\circ} \mathrm{K}\right)$. However, it does not mean that in the solid state polymerization, PET of ultrahigh molecular weight has to be obtained at the highest allowable reaction temperature. Theoretically, the sample would eventually reach the same molecular weight as long as the reaction temperature is kept above $175^{\circ} \mathrm{C}\left(448^{\circ} \mathrm{K}\right)$. Effect of Reaction Time

As shown in figure 2, the solid-state polymerization was carried out at $250^{\circ} \mathrm{C}\left(523^{\circ} \mathrm{K}\right)$ and the number-average molecular weights of the final products were plotted against the reaction time. There is an optimum time (about 40 hours in this case) for the process to reach the stage of maximum molecular weight, 120000 . Beyond this point the curve falls instead of remaining flat. Since under the condition of solid-state polymerization, cyclic compounds can hardly be formed, the decrease in molecular weight apparently is due to chain degradations which become predominant as the reaction time gets longer. The most probable degradation is the thermal type (ref. 8) which may be minimized by adopting a relatively lower reaction temperature. Oxidative and hydrolytic degradations (refs. 16 and 17) due to the small amount of oxygen and moisture content in the carrier gas, cannot be ruled out. These side reactions can be eliminated by passing the inert 
gas through a train of absorption columns containing copper filings heated to above $500^{\circ} \mathrm{C}\left(773^{\circ} \mathrm{K}\right)$ and molecular sieves or silica gel. Effect of PET Particle Size

Figure 3 indicates that increased molecular weight is obtained by decreasing the PET particle size. Since decreasing the particle size not only increases the reaction sites of polymerization but also facilitates the removal of ethylene glycol, the result of the effect of particle size is expected.

\section{Effect of Gas Flow Rate}

Figure 4 shows the variation of molecular weight with the nitrogen gas flow rate. It can be seen that there is an optimum value of the flow rate above which only a modest increase in molecular weight is obtained. The optimum value was found in this study to be 500 $\mathrm{m} l / \min$

\section{Effect of Nature of Carrier Gas}

The effectiveness of carrier gas on the molecular weight increase is given in table $\mathrm{V}$. The increasing order of $\mathrm{N}_{2}, \mathrm{CO}_{2}$, and $\mathrm{He}$ is rather interesting. If the carrier gas simply functioned as the carrier for ethylene glycol vapor, there should have been no significant difference in the final molecular weights. In other words, their influence on the molecular weight increase should be nearly equal. If the desorption of the ethylene glycol molecules from PET were affected only by the diffusion of the gas through the solid phase, their effectiveness should be inversely proportional 
to their molecular sizes and would be in the increasing order of $\mathrm{CO}_{2}<\mathrm{N}_{2}<\mathrm{He}$. The discrepancy could arise from the intermolecular forces of attraction between ethylene glycol and the gases, which are expected to be $\mathrm{He} \leq \mathrm{N}_{2}<\mathrm{CO}_{2}$. Because of these two main factors, diffusion and intermolecular forces, the experimental findings, $\mathrm{N}_{2}<$ $\mathrm{CO}_{2}<\mathrm{He}$, appears reasonable.

Extensions of Solid-State Polymerization Using

A Gas Chromatograph Apparatus

Following the program discussed in this report, additional PET was polymerized on a larger scale by using the 4-inch $0 . \mathrm{D}$. (0.1 m) columns, up to 20 pounds per operation (about $10 \mathrm{~kg}$ ) could be processed in this fashion. A number-average molecular weight of 68000 was obtained from a 20 pound (about $10 \mathrm{~kg}$ ) sample of Celanese PET polymerized at $250^{\circ} \mathrm{C}\left(523^{\circ} \mathrm{K}\right)$ for 48 hours and with a helium flow rate of $1 \mathrm{l} / \mathrm{min}$.

It is my opinion that with selection of the proper polymerization variables, this larger scale process could be used to synthesize PET with a number-average molecular weight in the order of 120000 .

In adition to using the gas chromatograph apparatus for the solid state polymerization of PET, it is noted that the process should also be suitable for synthesizing ultra-high molecular weight products of other condensation type polymers such as other polyesters, polyamides, polymides, etc. 


\section{CONCLUSION}

The results of the investigation of the solid-state polymerization of PET performed with a gas chromatograph show that the final product of number-average molecular weight in excess of 120000 may be obtained from commercial grade materials by adopting the most favorable combination of the parameters studied. Ester interchange catalysts such as tetraisopropyl titanate, zinc acetate-antimony trioxide, and cobaltous acetate are all capable of increasing the molecular weight of PET. Smaller particle size and higher molecular weight of the starting material are essential for achieving the ultrahigh molecular weight product. The preferable reaction temperature is between $200^{\circ} \mathrm{C}$ and $250^{\circ} \mathrm{C}\left(473^{\circ} \mathrm{K}\right.$ and $\left.523^{\circ} \mathrm{K}\right)$. The optimum reaction time depends upon other polymerization variables including the column size of the gas chromatograph. Molecular weights are also increased by increasing the gas flow rate up to optimum value which varies with other polymerization conditions. The effectiveness of the inert gas on the molecular weight increase is $\mathrm{N}_{2}<\mathrm{CO}_{2}<\mathrm{He}$. It was found that the process for solid state polymerization could be readily scaled up to prepare relatively large quantities (up to at least 20 pounds per operation (about $10 \mathrm{~kg}$ ) of ultra high molecular weight PET by using 4-inch O.D. $(0.1 \mathrm{~m})$ columns. 
REFERENCES

1. Mowers, R. E.; Lieb, J. H.; Sherman, S. ; Davenport, C. K. ; and Reiner, P. J.: Final Report, Program of Testing Nonmetallic Materials at Cryogenic Temperatures. Rep. No. R-3498, Rocketdyne Div., North American Aviation, Dec. 30, 1962.

2. Bell, J. E.; Killian, W. R.; Penner, J. E.; Pope, D. H.; Sutton, H. E. ; and Tweed, R. M.: Development of Positive Expulsion Systems for Cryogenic Fluids. Eng. Rep. No. 13511 (AFSSDTDR-62-14), Beech Aircraft Corp., May 1962.

3. Hanson, Morgan P.; Richards, Hadley T.; and Hickel, Robert O.: Preliminary Investigation of Filament-Wound Glass-Reinforced Plastics and Liners for Cryogenic Pressure Vessels. NASA TN D-2741, 1965.

4. Mark, H. F.: Polymers in Material Science. J. Polymer Sci., Part C, no. 9, 1965, pp. 1-33.

5. Sorenson, Wayne R.; and Campbell, Tod W.: Poly(ethylene terephthalate). Preparative Methods of Polymer Chemistry. Interscience Publishers, 1961, p. 113.

6. Cramer, Francis B.: Poly(ethylene terephthalate). Macromolecular Syntheses. Vol. 1. C. G. Overberger, ed., John Wiley \& Sons, Inc., 1963, pp. 17-21. 
7. Smith, James G.; Kibler, Charles J.; and Sublett, Bobby J.:

Preparation and Properties of Poly(methylene terephthalates).

J. Polymer Sci., Part A-I, vol. 4, no. 7, 1966, pp. 1851-1859.

8. Goodman, I.; and Rhys, J. A. : Polyesters. Vol. I. American Elsevier, 1965, ch. 3.

9. Flory, Paul J.: Principles of Polymer Chemistry. Cornel University Press, 1953, ch. 3.

10. Korshak, V. V.; and Vinogradova, S. V.: Polyesters. Pergamon Press, 1964, ch. 6.

11. Hashimoto, Shizunobu; and Sakai, Junichi: Formulation of Cyclic Ethylent Terephthalate Oligomers by the Thermal Degradation of Poly(ethylene Terephthalate). Kobunshi Kagaku, vol. 23, no. 254, 1966, pp. 422-425.

12. Anon.: Model 775 Prepmaster Instruction Manual. F and M Scientific, Division of Hewlet Packard Company.

13. Coover, H. W., Jr.; Joyner, F. B. ; and Shearer, N. H., Jr. :

Solid Phase Process for Linear Superpolyesters. U. S. Patent $3,075,952,1963$.

14. Griehl, W.; and Schnock, Gunther: The Kinetics of Polyester Formation by Transesterification. J. Polymer Sci., vol. 30, 1958, pp. 413-422.

15. Wilfong, R. E.: Linear Polyesters. J. Polymer Sci., vol. 54, 1961, pp. 385-410.

16. Buxbaum, L. H.: Reaction of Molecular Oxygen with Poly(ethylene terephthalate). Polymer preprints, Miami Beach Meeting, American Chemical Society, 1967, p. 552. 
$-14-$

17. Marshall, I.; and Todd, A.: The Thermal Degradation of Polyethylene terephthalate. Trans. Faraday Soc., vol. 49, 1953, pp. 67-78. 


\begin{tabular}{|c|c|c|c|c|c|c|c|c|c|c|c|}
\hline 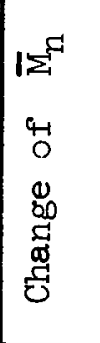 & 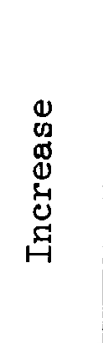 & $\stackrel{\rho}{z}$ & $\stackrel{\circ}{z}$ & 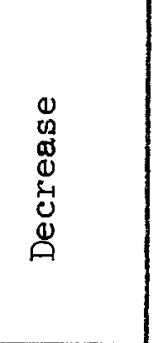 & 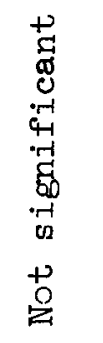 & $\stackrel{O}{Z}$ & 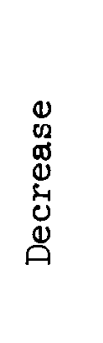 & 完 & 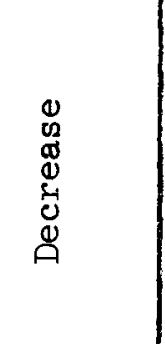 & $\hat{z}$ & 号 \\
\hline 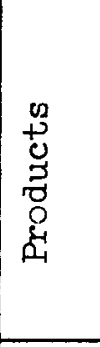 & 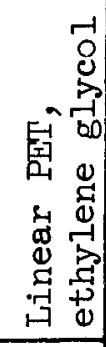 & 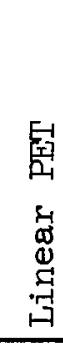 & 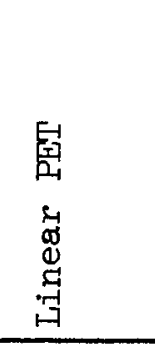 & 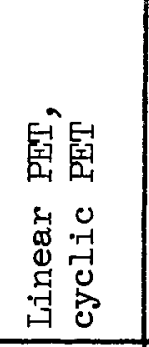 & 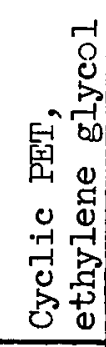 & 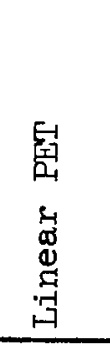 & 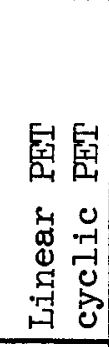 & 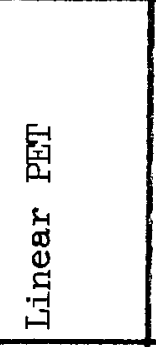 & 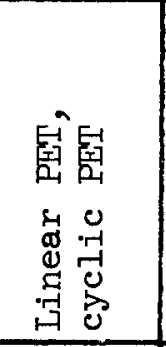 & 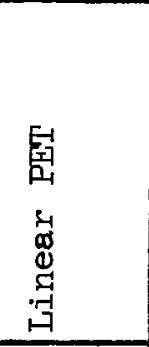 & 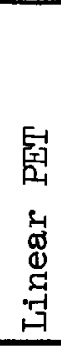 \\
\hline 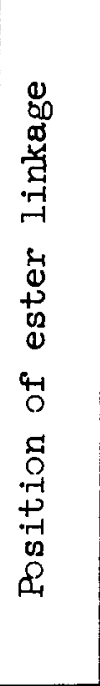 & 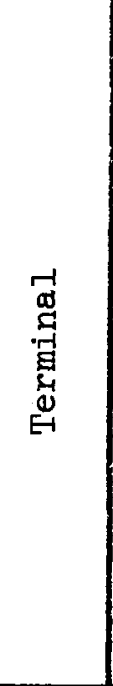 & 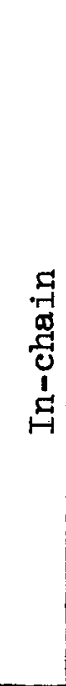 & 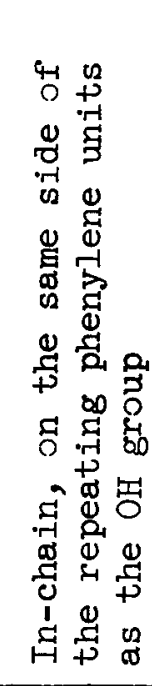 & 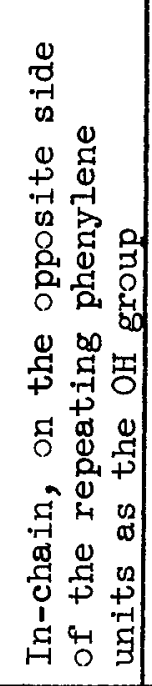 & 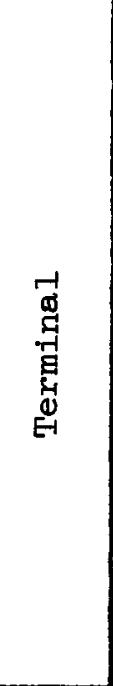 & 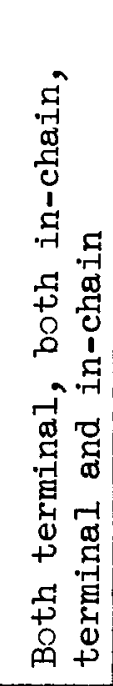 & 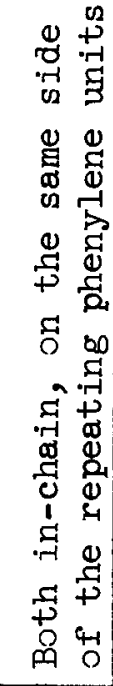 & 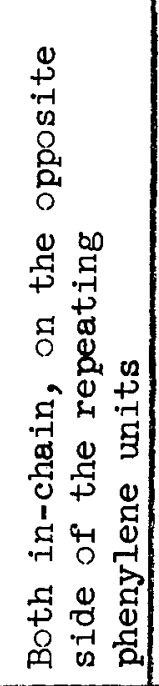 & 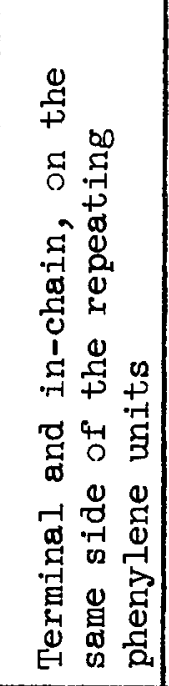 & 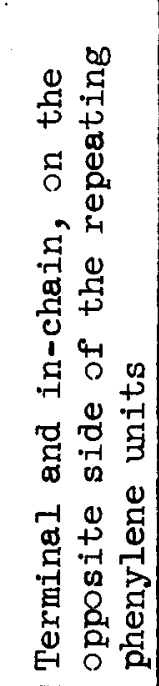 & 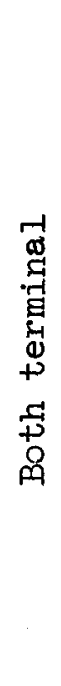 \\
\hline 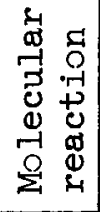 & 离 & 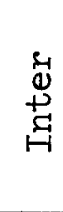 & 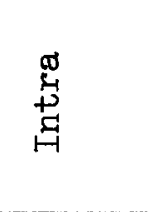 & 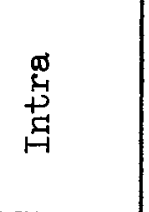 & 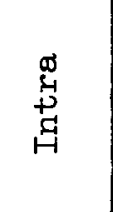 & 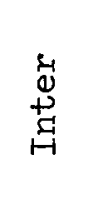 & 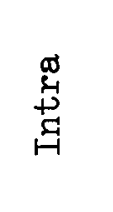 & 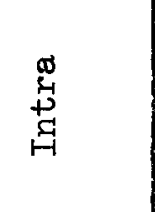 & 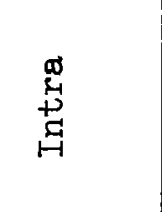 & 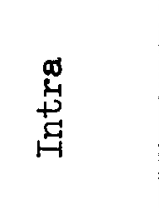 & 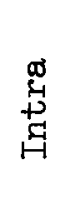 \\
\hline 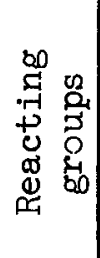 & $\begin{array}{c}1 \\
0 \\
1 \\
1 \\
1 \\
0 \\
0 \\
1\end{array}$ & $\begin{array}{l}1 \\
0 \\
=0 \\
1 \\
1 \\
0 \\
0 \\
1\end{array}$ & $\begin{array}{c}0_{1}^{1} \\
0=0 \\
1 \\
y_{1}^{\prime}\end{array}$ & $\begin{array}{c}1 \\
0 \\
0=0 \\
1 \\
1 \\
1 \\
0\end{array}$ & $\begin{array}{c}0 \\
0 \\
1 \\
0=0 \\
1 \\
\text { 氙 } \\
1\end{array}$ & $\begin{array}{c}0 \\
0 \\
0=0 \\
1 \\
0 \\
0 \\
0=0 \\
1\end{array}$ & $\begin{array}{r}1 \\
0 \\
0=0 \\
1 \\
0 \\
0 \\
0=0 \\
1\end{array}$ & $\begin{array}{c}1 \\
0 \\
1 \\
0=0 \\
1 \\
0 \\
0=0 \\
1\end{array}$ & $\begin{array}{c}0 \\
0=0 \\
1 \\
1 \\
0=0 \\
0 \\
1\end{array}$ & $\begin{array}{c}0 \\
0=0 \\
1 \\
0 \\
0=0 \\
1 \\
1\end{array}$ & $\begin{array}{r}0 \\
1 \\
0=0 \\
1 \\
0 \\
0 \\
0=0 \\
1\end{array}$ \\
\hline$\dot{\rho}$ & $\mapsto$ & $\stackrel{H}{H}$ & 吕 & P & $>$ & $\stackrel{-1}{p}$ & $\stackrel{H}{-}$ & $\stackrel{H}{\stackrel{H}{-}}$ & H & $\times$ & 㫐 \\
\hline
\end{tabular}


$-16-$

TABIE II. - PET SAMPIES

\begin{tabular}{|l|l|c|c|c|}
\hline \multicolumn{1}{|c|}{ Source } & Form & Catalyst & m.p. ${ }^{\circ} \mathrm{C}\left(\mathrm{O}_{\mathrm{K}}\right)$ & $\overline{\mathrm{M}}_{\mathrm{n}}$ \\
\hline Dupont & Flake & Unknown & $254-256(527-529)$ & 15300 \\
Celanese Plastic & Chip & Unknown & $256-258(529-531)$ & 16500 \\
NASA-Lewis & Lump & $\mathrm{Ti}\left[\mathrm{O} \mathrm{CH}\left(\mathrm{CH}_{3}\right)_{2}\right]_{4}$ & $256-258(529-531)$ & 2400 \\
NASA-Iewis & Lump & $\mathrm{Zn}(\mathrm{OAc})_{2-\mathrm{Sb}_{2} \mathrm{O}_{3}}$ & $254-256(527-529)$ & 8400 \\
NASA-Iewis & Lump & $\mathrm{Co}(\mathrm{OAc})_{2}$ & $248-250(521-523)$ & 2000 \\
\hline
\end{tabular}

TABIE III. - CARRIER GAS

\begin{tabular}{|l|c|c|c|}
\hline $\begin{array}{c}\text { Carrier } \\
\text { gas }\end{array}$ & $\begin{array}{c}\text { Purity, } \\
\text { Mole \% }\end{array}$ & $\begin{array}{c}\mathrm{O}_{2} \text { Content, } \\
\mathrm{ppm}\end{array}$ & $\begin{array}{c}\mathrm{H}_{2} \mathrm{O} \text { content, } \\
\mathrm{ppm}\end{array}$ \\
\hline $\mathrm{N}_{2}$ & 99.9 & $7-8$ & 2 \\
$\mathrm{CO}_{2}$ & 99.5 & ${ }^{*} 146$ & ${ }^{*} 127$ \\
$\mathrm{He}$ & $>99.99$ & $<$ & 2 \\
\hline
\end{tabular}

*Analyzed at NASA-Lewis Research Center. 
TABLE IV. - EFFECT OF CATALYST ON SOLID STATE POLYMERIZATION ${ }^{\circledR}$ OF PET ${ }^{\mathrm{b}}$ USING GAS CHROMATOGRAPHIC APPARATUS ${ }^{\mathrm{C}}$

\begin{tabular}{|c|c|c|c|}
\hline \multirow{2}{*}{$\begin{array}{c}\text { PET } \\
\text { Sample }\end{array}$} & \multirow[t]{2}{*}{ Catalyst } & \multicolumn{2}{|c|}{ Number average molecular weight } \\
\hline & & Initial & Final \\
\hline $\operatorname{III}^{\mathrm{d}}$ & Unknown & 15300 & 80000 \\
\hline$I V^{e}$ & Unknown & 16500 & 104000 \\
\hline$I^{f}$ & Tetraisopropyltitanate & 2400 & 18000 \\
\hline$I I^{f}$ & $\begin{array}{l}\text { Zinc acetate and } \\
\text { antimony trioxide }\end{array}$ & 8400 & 65000 \\
\hline$V^{f, g}$ & Cobaltous acetate & 20000 & $\mathrm{~h}_{120} 000$ \\
\hline
\end{tabular}

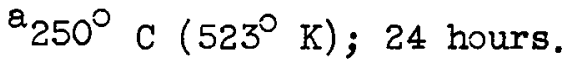

${ }^{\mathrm{b}}$ Particle diameter $0.18-0.25 \mathrm{~mm}$.

cColumn size $16^{\prime} \times 3 / 4^{\prime \prime}$ O.D. $(4.9 \mathrm{~m} \times 1.9 \mathrm{~cm} \mathrm{0.D.)}$; Nitrogen gas flow rate, $350 \mathrm{ml} / \mathrm{min}$.

dobtained from Du Pont Co.

eobtained from Celanese Plastic Company.

${ }^{f}$ Prepared at NASA Lewis Research Center.

$8_{230^{\circ}} \mathrm{C}\left(503^{\circ} \mathrm{K}\right)$; Nitrogen for 24 hours and helium for 12 hours.

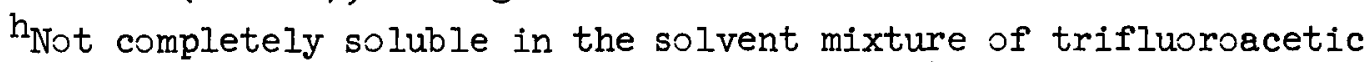
acid and methylene chloride (1:1 by volume). 
TABLE V. - EFFECT OF CARRIER GAS ON SOLID STATE POLYMERIZATION ${ }^{\mathrm{a}}$ OF PET ${ }^{\mathrm{b}}$ USING GAS CHROMATOGRAPHIC APPARATUSC

\begin{tabular}{|l|c|}
\hline Carrier gas & Number average molecular weight \\
\hline Nitrogen & 58000 \\
Carbon Dioxide & 81000 \\
Helium & 90000 \\
\hline
\end{tabular}

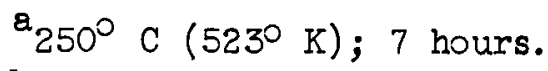

bobtained from Celanese Plastic Company; Initial number average molecular weight I6 500; Particle diameter $0.18-0.25 \mathrm{~mm}$.

${ }^{C}$ Column size 16' $\times 3 / 4^{\prime \prime}$ O.D. (4.9 m $\times 1.9 \mathrm{~cm} \mathrm{O.D.);}$ Gas flow rate $350 \mathrm{~m} / \mathrm{min}$. 


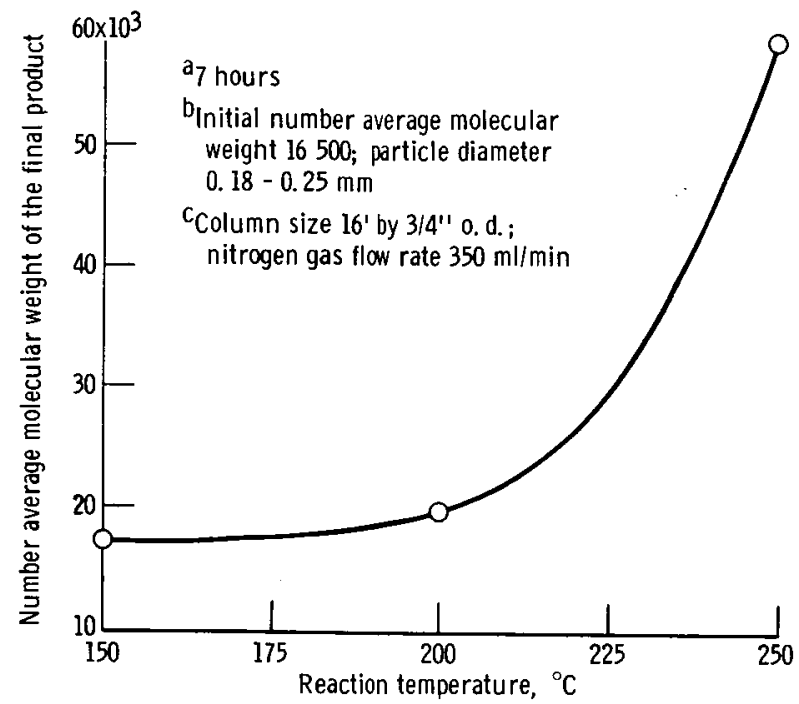

Figure 1. - Effect of reaction temperature on solid state polymerization ${ }^{\mathrm{a}}$ of $\mathrm{PET}^{\mathrm{b}}$ using gas chromatograph apparatus $\mathrm{c}^{\mathrm{C}}$.

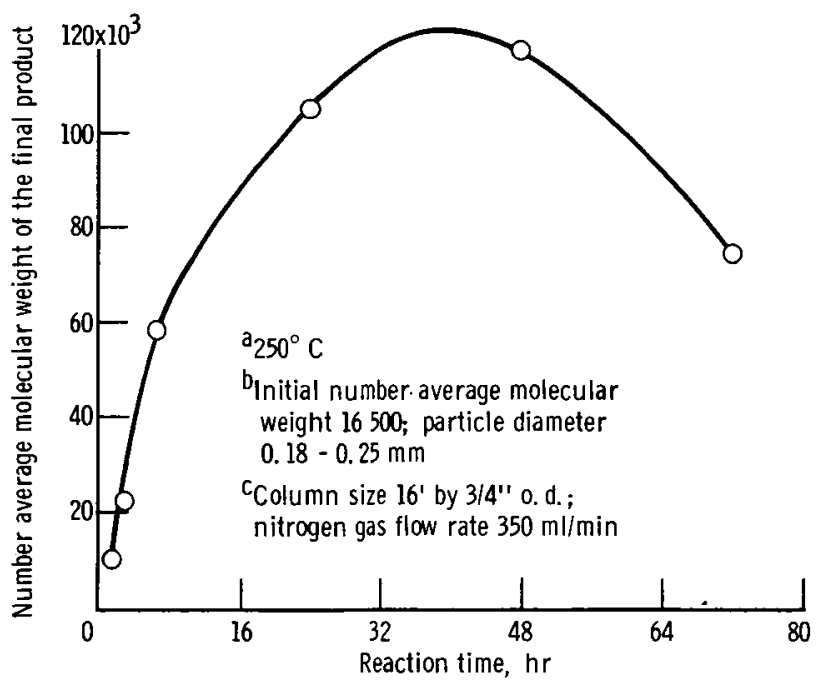

Figure 2. - Effect of reaction time on solid state polymerization ${ }^{\text {a }}$ of $\mathrm{PET}^{\mathrm{B}}$ using gas chromatograph apparatus ${ }^{\mathrm{C}}$. 


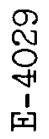

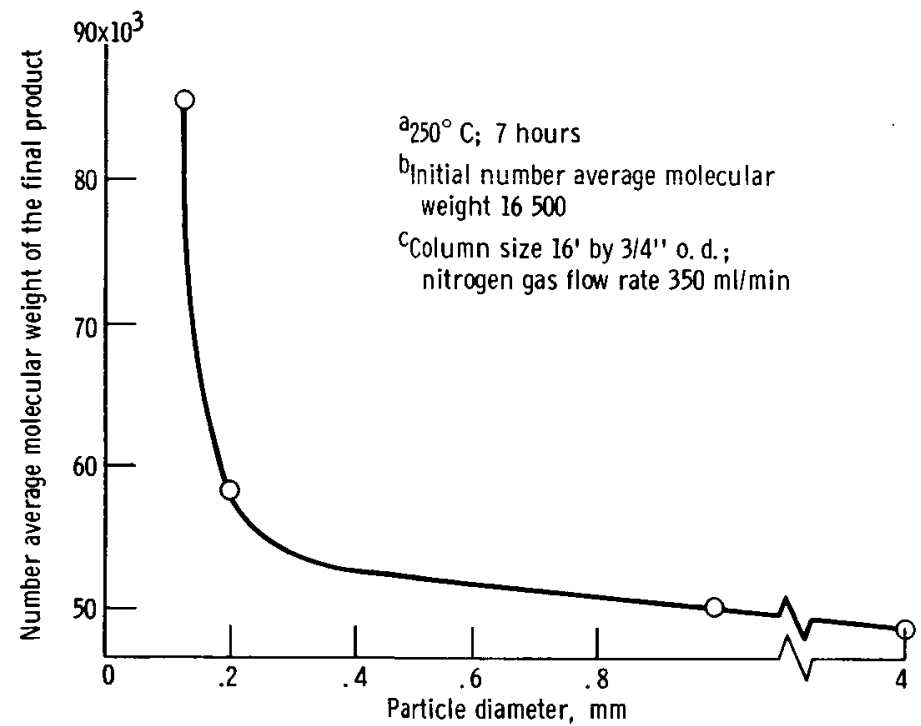

Figure 3. - Effect of particle size on solid state polymerization ${ }^{\mathrm{a}}$ of $\mathrm{PET}^{\mathrm{b}}$ using gas ch romatograph apparatus ${ }^{\mathrm{C}}$.

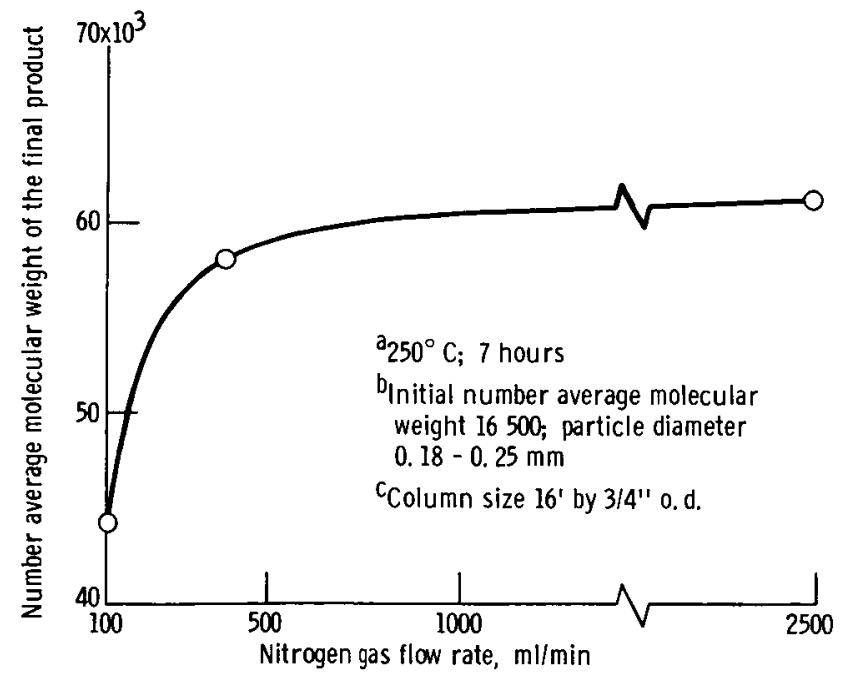

Figure 4. - Effect of nitrogen gas flow rate on solid state polymerization ${ }^{a}$ of $\mathrm{PET}^{\mathrm{b}}$ using gas chromatograph apparatus ${ }^{\mathrm{C}}$. 